\title{
Construction of one new coordination polymers based on 5-(pyridin-4-yl)isophthalic acid acid ligands: synthesis, crystal structures and magnetism
}

\author{
Ya-Ning Wang ${ }^{1, a}$, Shi-Jie Li ${ }^{1, b^{*}}$, Wen-Dong Song ${ }^{1, \mathrm{c}^{*}}$ \\ ${ }^{1}$ Innovation Application Institute, Zhejiang Ocean University, Zhoushan, Zhejiang, 316004, China \\ awyn198399@126.com, ${ }^{\text {b., }}{ }^{*}$ Isj19850530@sina.com, ${ }^{c,}$ swd60@163.com
}

Keywords: 5-(pyridin-4-yl)isophthalic acid; coordination polymer; magnetism

Abstract: One new coordination polymer, namely, $\left\{\left[\mathrm{Co}(\mathrm{Ll}) \mathrm{H}_{2} \mathrm{O}\right] \cdot \mathrm{H}_{2} \mathrm{O}\right\}_{n} \quad 1 \quad[\mathrm{LI}=5-$ (pyridin-4-yl)isophthalic acid], has been synthesized under hydrothermal conditions and characterized by elemental analysis, IR spectroscopy, X-ray diffraction and thermogravimetric analysis. In compound 1 , three oxygen atoms and one nitrogen atoms of the ligand, a T-shaped linker, coordinate to four metals centers to form an infinite double-layer structures, exhibiting extended 3D supramolecular network via $\mathrm{O}-\mathrm{H} \cdots \mathrm{O}$ hydrogen bonding interactions.

\section{Introduction}

Construction of novel metal-organic coordination polymers with desired properties has been one of the current hot topics of materials research due to their potential application in photoluminescence, magnetism, ion exchange, gas absorption /separation, catalysis, and so on[1-4]. However, it is still a great challenge to predict and further accurately control the complicated architectures because of the relative unpredictability in the assemble process. To generate a fascinating configuration, the judicious selection of an organic ligand with changeable bridging length, conformation and flexibility is a very important strategy[5].

5-(pyridin-4-yl)isophthalic acid as multifunctional ligands are supposed to be excellent candidates for generating coordination polymers with intriguing variety of architectures. Here in we report one new 2D coordination polymers based on the 5-(pyridin-4-yl)isophthalic acid(L1), namely: $\left\{\left[\mathrm{Co}(\mathrm{Ll}) \mathrm{H}_{2} \mathrm{O}\right] \cdot \mathrm{H}_{2} \mathrm{O}_{n} \mathrm{l}\right.$. $\mathrm{l}$ is $2 \mathrm{D}$ double-layer networks, displaying $3 \mathrm{D}$ framework via hydrogen bonding interactions.

\section{Experimental}

\section{Materials and equipment}

All chemicals were commercially available and used without further purification. Elemental (C, $\mathrm{H}, \mathrm{N}$ ) analyses were performed on Perkin-Elmer $240 \mathrm{CHN}$ element analyzer. Infrared (IR) spectra were recorded $\left(4000 \sim 400 \mathrm{~cm}^{-1}\right)$ as $\mathrm{KBr}$ disks on a Bruker 1600 FTIR spectrometer. Thermogravimetric analysis (TGA) experiments were carried out on a Perkin-Elmer TG/DTA 6300 system with a heating rate of $10{ }^{\circ} \mathrm{C} / \mathrm{min}$ from room temperature to $800{ }^{\circ} \mathrm{C}$ under nitrogen atmosphere. Temperature-dependent magnetic measurements were carried out on a Quantum Design MPMS XL-7 magnetometer at an applied field of 2 KOe in the temperature range of 2 to $300 \mathrm{~K}$.

\section{Synthesis of the complexes complex 1}

$\left\{\left[\mathrm{Co}(\mathrm{Ll}) \mathrm{H}_{2} \mathrm{O}\right] \cdot \mathrm{H}_{2} \mathrm{O}_{n}\left(\mathrm{Ll}=5\right.\right.$-(pyridin-4-yl)isophthalic acid) (1): A mixture of $\mathrm{Co}\left(\mathrm{NO}_{3}\right)_{2} \cdot 6 \mathrm{H}_{2} \mathrm{O}$ (0.07 g, $0.25 \mathrm{mmol}), 5$-(pyridin-4-yl)isophthalic acid $(0.12 \mathrm{~g}, 0.5 \mathrm{mmol})$ and $\mathrm{H}_{2} \mathrm{O}(10 \mathrm{~mL})$ was stirred for $10 \mathrm{~min}$ in air at room temperature, with the $\mathrm{pH}$ of 7 adjusted by $\mathrm{NaOH}$, and then sealed in a $20 \mathrm{~mL}$ teflon reactor and kept under autogenous pressure at $120^{\circ} \mathrm{C}$ for $72 \mathrm{~h}$. The mixture was cooled to room temperature at a rate of $5^{\circ} \mathrm{C} \mathrm{h}^{-1}$ and purple plate crystals were obtained in a yield of 
$47 \%$ based on Co. Calcd for $\mathrm{C}_{13} \mathrm{H}_{11} \mathrm{~N}_{1} \mathrm{O}_{6} \mathrm{Co}$, Anal. found (\%): C, 46.32; H, 3.33; N, 4.21. Calcd. (\%): C, 46.41; H, 3.27; N, 4.16. IR bands (KBr pellets, $\left.\mathrm{cm}^{-1}\right)$ : 3335(vs), 1616(s), 1577(w), 1548(w), 1510(w), 1459(s), 1427(w), 1408(w), 1338(s), 1304(w), 1279(w), 1230(w), 1157(w), 1082(m), 1026(m), 917(w), 842(w), 775(w), 722(w), 647(w), 543(w), 506(w), 467(w).

\section{$\mathrm{X}$-ray diffraction determination}

Diffraction data of the compounds 1 was recorded on a Bruker SMART CCD 1000 diffractometer operating at $50 \mathrm{kV}$ and $30 \mathrm{~mA}$ using Mo- $K \alpha$ radiation $(\lambda=0.71073 \AA)$ at $298(2) \mathrm{K}$. Data collection and reduction were performed using the SMART and SAINT software[6], multi-scan absorption correction was applied using the SADABS program[6]. The structures were solved by direct methods and refined by full-matrix least-squares techniques using the SHELXTL program package[7]. All non-hydrogen atoms were treated anisotropically. Crystal data and details of the data collection and refinement for 1 are listed in table 1 .

Table 1. Crystal data and structure refinement for 1

\begin{tabular}{|c|c|}
\hline Compounds & 1 \\
\hline Empirical Formula & $\mathrm{C}_{13} \mathrm{H}_{11} \mathrm{NO}_{6} \mathrm{Co}$ \\
\hline Formula weight & 336.16 \\
\hline Crystal size (mm) & $0.15 \times 0.09 \times 0.05$ \\
\hline Crystal System & triclinic \\
\hline Space group & $P \overline{1}$ \\
\hline$a(\AA)$ & $7.2413(8)$ \\
\hline$b(\AA)$ & $10.0757(13)$ \\
\hline$c(\AA)$ & $10.2121(12)$ \\
\hline$\alpha\left(^{\circ}\right)$ & $113.807(2)$ \\
\hline$\beta\left({ }^{\circ}\right)$ & $99.7030(10)$ \\
\hline$\gamma\left({ }^{\circ}\right)$ & $104.2390(10)$ \\
\hline$V\left(\AA^{3}\right)$ & $629.89(13)$ \\
\hline$Z$ & 1 \\
\hline$F(000)$ & 342 \\
\hline$D_{\text {calc }}\left(\mathrm{mg} / \mathrm{cm}^{3}\right)$ & 1.772 \\
\hline Absorption coefficient $\left(\mathrm{mm}^{-1}\right)$ & 1.391 \\
\hline GOF & 0.980 \\
\hline$\theta$ range for data collection $\left(^{\circ}\right)$ & 2.29 to 25.00 \\
\hline Limiting indices & $-8 \leq \mathrm{h} \leq 8,-10 \leq \mathrm{k} \leq 11,-10 \leq 1 \leq 12$ \\
\hline Reflections collected / unique & $3312 / 2186$ \\
\hline Completeness to $\theta=25.00$ & $98.6 \%$ \\
\hline Data/restraints/parameters & $2186 / 7 / 190$ \\
\hline Final $R$ indices $[\mathrm{I}>2 \sigma(\mathrm{I})]$ & $\mathrm{R} 1=0.0539, \mathrm{wR} 2=0.1175$ \\
\hline$R$ indices (all data) & $\mathrm{R} 1=0.0793, \mathrm{wR} 2=0.1284$ \\
\hline
\end{tabular}




\section{Results and discussion}

\section{Crystal structure of 1 .}

Single-crystal X-ray diffraction analysis reveals that compound 1 crystallizes in triclinic space group $\mathrm{P} \overline{1}$, and the asymmetric unit of 1 consists of one Co(II) ion, one L1 ligand, one coordinated water molecule and one solvate water molecule. Each distorted octahedral Co(II) ion is six-coordinated by two chelating carboxylate oxygen atoms from one L1 ligand, two bidentate carboxylate oxygen atoms and one pyridyl nitrogen atom from another three L1 ligands, and one coordinated water molecule (figure 1a). The Co-N bond length is 2.079(4) $\AA$, the Co-O bond lengths and O-Co-O angles are varying from 2.023(3) $\AA$ to $2.260(3) \AA$ and $60.03(12)^{\circ}$ to $170.38(13)^{\circ}$, respectively. Compared with the ligand adopting $\mu_{6}$-coordination mode in the nanotubular metal-organic framework, each ligand connects four Co atoms through two carboxylate groups and one pyridyl nitrogen atom. The coordination modes of two carboxylate groups differ from each other. One carboxylate group coordinates to one Co ion in the $\mathrm{O}, \mathrm{O}$ '-chelating mode and the other bridges another two Co ions via one carboxylate oxygen. The adjacent two Co ions are bridged by two carboxylate oxygen atoms to form a binuclear $\left[\mathrm{Co}_{2} \mathrm{O}_{2}\right]$ cluster with Co-Co distance of 3.357(3) $\AA$, which can be seen as a secondary building unit (SBU). Significantly, the L1 ligands exhibit a twisted fashion to link each $\left[\mathrm{Co}_{2} \mathrm{O}_{2}\right]$ cluster to six neighboring $\left[\mathrm{Co}_{2} \mathrm{O}_{2}\right]$ clusters with a dihedral angle of $33.5^{\circ}$ between the benzene and byridyl ring of the ligand. As a consequence, a 2D double-layer network parallel to $b c$-plane is constructed (figure 1b). And the adjacent layers are interconnected into a 3D supramolecular network via $\mathrm{O}-\mathrm{H} \cdots \mathrm{O}$ hydrogen bonding interactions among the carboxylate oxygen atoms, the coordinated water molecules and the solvate water molecules $[8,9]$ (figure 1c).

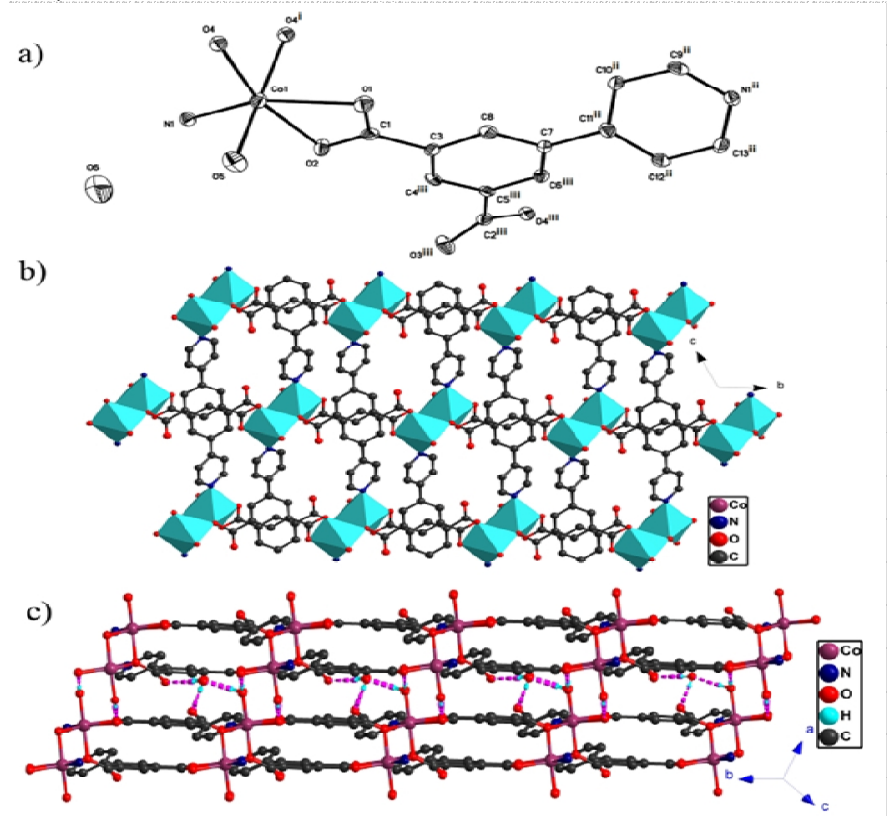

Figure 1. (a) Thermal ellipsoid plot of the asymmetric unit of 1 (30\% probability ellipsoids), (b) View of 2D double layer parallel to $b c$-plane, and (c) View of 3D supramolecular network constructed by O-H $\cdots$ O hydrogen bonding interactions. Symmetry codes for $1: \mathrm{i}=-\mathrm{x}+1,-\mathrm{y}+1,-\mathrm{z}+1$; ii $=\mathrm{x}, \mathrm{y}+1, \mathrm{z}$; iii $=\mathrm{x}, \mathrm{y}-1, \mathrm{z}$.

\section{Thermogravimetric analyses of compound 1}

Thermogravimetric analyses (TGA) were performed to verify the thermal stabilities of complexe 1 (figure $2 \mathrm{a}$ ). Both complexes showed relatively high thermal stabilities. TGA shows that 1 is stable up to $420^{\circ} \mathrm{C}$. The weight loss of $5.41 \%$ from 150 to $245{ }^{\circ} \mathrm{C}$, corresponds to the loss of one coordinated water molecule and one solvate water molecule per formula unit (calcd 5.35\%). There is no weight loss from $245^{\circ} \mathrm{C}$ to $420^{\circ} \mathrm{C}$. No further weight losses were observed. 

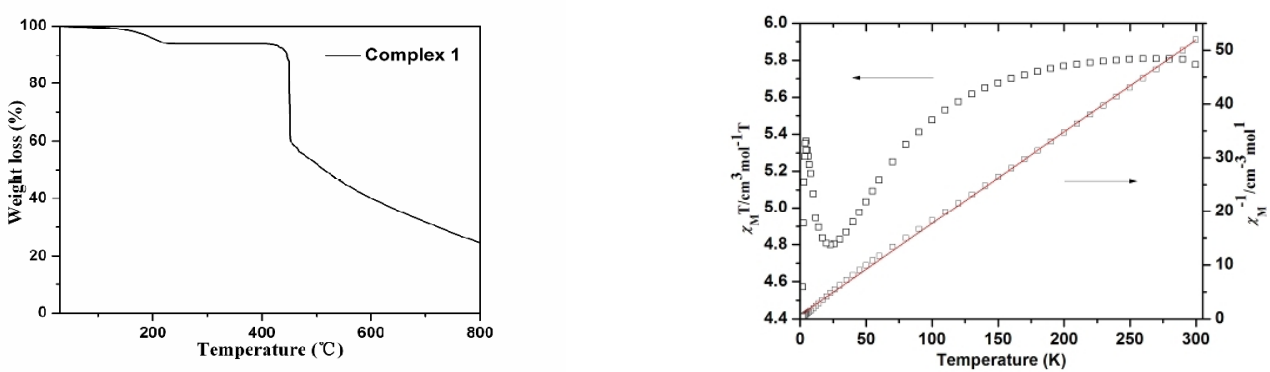

Figure 2. (a) The TGA trace of complex 1 , (b) The plot of temperature dependence of $\chi_{\mathrm{M}} \mathrm{T}$ and $\chi_{\mathrm{M}}{ }^{-1}$ under a $2 \mathrm{kOe}$ field for 1

\section{Magnetic properties}

The temperature dependence of magnetic susceptibility of 1 was carried out using a Quantum Design MPMS XL-7 magnetometer in an applied magnetic field of $2 \mathrm{KOe}$ in the temperature range of 2 to $300 \mathrm{~K}$.

Variable-temperature magnetic susceptibility in the forms of $\chi_{\mathrm{M}} T$ and $\chi_{\mathrm{M}}{ }^{-1}$ versus $T$ curves for 1 are shown in figure $2 \mathrm{~b}$. At $300 \mathrm{~K}$, the value of $\chi_{\mathrm{M}} \mathrm{T}$ per $\mathrm{Co} 2$ unit is $5.80 \mathrm{~cm}^{3} \mathrm{~K} \mathrm{~mol}^{-1}$, which is larger than the expected spin-only value of $3.75 \mathrm{~cm}^{3} \mathrm{~K} \mathrm{~mol}^{-1}$ for two high-spin Co(II) centers with $\mathrm{S}=3 / 2$, indicating a significant orbital contribution.Upon cooling, $\chi_{\mathrm{M}} \mathrm{T}$ values decrease continuously to a valley value of $4.8 \mathrm{~cm}^{3} \mathrm{~K} \mathrm{~mol}^{-1}$ around $23 \mathrm{~K}$. Then further cooling, it increases to a peak value of $4.36 \mathrm{~cm}^{3} \mathrm{~K} \mathrm{~mol}^{-1}$ at $4.5 \mathrm{~K}$, afterwards a rapidly drop toward the minimum value of $4.57 \mathrm{~cm}^{3} \mathrm{~K}$ $\mathrm{mol}^{-1}$ at $2 \mathrm{~K}$. The upswing behave of $\chi_{\mathrm{MT}}$ below $23 \mathrm{~K}$ indicates a possible magnetic phase transition. The fitting of the $\chi_{\mathrm{M}}{ }^{-1}$ data from 10 to $300 \mathrm{~K}$ with the Curie-Weiss law gives a Curie constant $\mathrm{C}=5.85 \mathrm{~cm}^{3} \mathrm{~K} \mathrm{~mol}^{-1}$ and Weiss constant $\theta=-3.78 \mathrm{~K}$. The big negative Weiss constant $\theta$ may also indicates the coexistence of antiferromagnetic interactions between adjacent $\mathrm{Co}$ (II) ions and/or partly the strong spin-orbit coupling.

\section{Conclusion}

One new 2D coordination polymers based on 5-(pyridin-4-yl)isophthalic acid has been synthesized and structurally and magnetically characterized. it exhibits 3D supramolecular network constructed of 2D layers via hydrogen bonding interactions. Magnetic studies reavealed that 1 shows possible coexistence of antiferromagnetic interactions between adjacent Co(II) ions and/or partly the strong spin-orbit coupling The results demonstrate that 5-(pyridin-4-yl)isophthalic acid ligand could be an excellent potential candidate for building novel coordination polymers with desired properties.

\section{Supplementary material}

CCDC 937520 contain the supplementary crystallographic data for this article.

\section{Acknowledgements}

This work was financially supported by the research startup foundation of Zhejiang Ocean University. 


\section{References}

[1] S. Hasegawa, S. Horike, R. Matsuda, S. Furukawa, K. Mochizuki, Y. Kinoshita and S. Kitagawa: J. Am. Chem. Soc. Vol. 129 (2007), p. 2607

[2] J.R. Li, R.J. Kuppler and H.C. Zhou: Chem. Soc. Rev. Vol. 38 (2009), p. 1477

[3] R.B. Getman , Y.S. Bae, C.E. Wilmer and R.Q. Snurr: Chem. Rev. Vol. 112 (2012), p. 703

[4] D. Zhao, S. Tan, D. Yuan, W. Lu, Y.H. Rezenom, H. Jiang, L.Q. Wang and H.C. Zhou: Adv. Mater. Vol.23 (2011), p. 90

[5] B.Y. Li, Z.J. Zhang, Y. Li, K.X. Yao, Y.H. Zhu, Z.Y. Deng, F. Yang and X.J. Zhou: Angew. Chem. Int. Ed. Vol. 50 (2011), p. 1

[6] Bruker. SMART, SAINT, and SADABS, Bruker AXS Inc., Madison, WI, (2007).

[7] G. M. Sheldrick: Acta Crystallogr. Sect. A Vol. 64 (2008), p.112.

[8] L.F. Ma, Y.F. Wang, L.Y. Wang, J.G. Wang and X. Feng: Z. Anorg. Allg. Chem. Vol. 632 (2006), p. 675

[9] P. Betz, A. Bino, J. L. Du, I. S. M. Lo and R. C. Thompson: Inorg. Chim. Acta. Vol. 170 (1990), p. 45 